\title{
Genotype, Temperature, and Fall-applied Ethephon Affect Plum Flower Bud Development and Ovule Longevity
}

\author{
Yerko M. Morenol and Anita Nina Miller-Azarenko² \\ Department of Horticulture, 2042 Cordley Hall, Oregon State University, Corvallis, \\ OR 97331-2911
}

\author{
William Potts ${ }^{3}$ \\ University of Maryland, U.S. Department of Agriculture Statistical Consulting Service, Beltsville, \\ MD 20705
}

\begin{abstract}
Additional index words. Prunus domestics, fluorescence microscopy, aniline blue, mineral nutrition, prune
Abstract. Flower bud growth and ovule longevity of plum (Prunus domestics L.) cultivars Italian and Brooks and the effects of fall-applied ethephon and of temperature were studied. Fresh and dry weights of terminal flower buds were measured at l-week intervals from 50 days to 1 day before bloom in 1988 . Buds were also analyzed for $\mathbf{N}$, $P$, $\mathrm{K}$, Ca, and $\mathrm{B}$. After bloom, ovule longevity was determined using a fluorescence method after staining with aniline blue. Ovule longevity was determined in $\mathbf{1 9 9 0}$ using shoots excised at full bloom from untreated and ethephon-treated trees of both cultivars and held in growth chambers for 18 days at 5, 10, 15, or 20C. 'Brooks' flower buds showed a higher accumulation of fresh and dry weight than 'Italian', and ethephon reduced bud weights in both cultivars. Ethephon did not affect mineral content of flower buds of 'Brooks', but 'Italian' flower buds contained a higher concentration of $\mathrm{Ca}$ and a lower concentration of $\mathrm{P}$ when treated with ethephon. Boron content was higher in the ethephon-treated buds of 'Italian' trees on some sampling dates. Ovule longevity was higher for 'Brooks' than for 'Italian' in both years. Ethephon treatment delayed ovule senescence in 'Italian' flowers, but had little or no effect on 'Brooks' flowers. Increasing temperatures induced faster ovule senescence in both cultivars. Chemical name used. 2-chloroethylphosphonic acid (ethephon).
\end{abstract}

Insufficient fruit set in plum trees may be due to a genetic predisposition for abnormal embryo sac development (Thompson and Liu, 1973), low temperature during and after bloom time (Jaumien, 1968), or B deficiency in the flowers that results in poor pollen tube growth (Hanson and Breen, 1985a). Poor fruit set may result from a shortened effective pollination period (EPP), the difference between ovule longevity and the time required for the pollen tube to reach the egg sac (Stösser and Anvari, 1982; Williams, 1966, 1970). A short EPP can result from slow pollen tube growth rates and/or short ovule longevity.

Fall ethephon applications delay flowering in several fruit tree species (Coston et al., 1985; Dennis, 1976; Gianfagna et al., 1986; Proebsting and Mills, 1973; Webster, 1986), but such treatments have often not resulted in increased fruit set and yield. The benefit of bloom delay is often decreased by side effects, such as gummosis, floral abscission, or failure of floral buds to open (Coston et al., 1985; Dennis, 1976; Proebsting and Mills, 1973). Crisosto et al. (1990) reported bloom delay but decreased yield in peaches [Prunus persica (L.) Batsch.]. Bloom was also delayed when ethephon was applied to 'Italian' prune (Crisosto et al., 1990). However, a significant increase in yield was observed in 1 year of trials. Durner et al. (1990) reported that in a 2-year trial, ethephon treatment enhanced yield of 'Cresthaven' peach in both years, but that of 'Jerseydawn' in only 1 year. Regardless of its effect on yield, the ethephon

Received for publication 25 Feb. 1991. Oregon Agricultural Experiment Station Technical Paper no. 9619. This research was funded by USDA Specific Cooperative Agreement 58-3464-7-055 and the Oregon Processed Prune and Plum Growers Commission, The cost of publishing this paper was defrayed in part by the payment of page charges. Under postal regulations, this paper therefore must be hereby marked advertisement solely to indicate this fact.

'Graduate Research Assistant.

${ }^{2}$ Associate Professor.

Statistician. treatment caused smaller pistils to develop and heavier prethinning crop loads, which led to smaller fruit and a later harvest date.

Temperatures up to 3 weeks after full bloom had a pronounced effect on the rate of 'Italian' prune embryo sac development and abortion (Thompson and Liu, 1973). Keulemans (1984) found the same relationship, but also that genotypes varied in sensitivity to cool postbloom temperatures. Shorter ovule longevity in warm than cool seasons adversely affects fertilization in sweet cherry [Prunus avium (L.) L.] (Eaton, 1959) and apple (Malus domestica Borkh.) (Dorsey, 1929; Williams, 1965). Cool weather may prolong ovule longevity, but retards pollen tube growth sufficiently so that fertilization is not possible before ovular breakdown (Williams, 1970).

The objectives of this study were to determine the effect of genotype and fall ethephon application on flower bud growth, mineral content of buds, and ovule longevity of flowers from the plum cultivars. 'Brooks' and 'Italian' were selected because of their consistent and erratic annual production, respectively. The effect of temperature on ovule viability of the two cultivars, with or without a fall ethephon application, was determined.

\section{Materials and Methods}

Ethephon was applied at 0 or $500 \mathrm{mg} \cdot$ liter $^{-1}$ to runoff with a hand gun sprayer to 'Italian' and 'Brooks' prune trees at the 60\% leaf drop stage on 9 Nov. 1988 and 26 Oct. 1989. Regulaid $[0.1 \%(\mathrm{v} / \mathrm{v})]$ was added to assist spreading. The orchard used in this study was planted in 1975 and located at the LewisBrown Horticulture Research Farm, Oregon State Univ., Corvallis. Ten single-tree replicates were used for each treatment.

Growth measurements. Three replicates of 100 terminal flower

Abbreviations: DAFB, days after full bloom, DW, dry weight FW, fresh weight. 
buds were excised from the terminal region of 2 to 3 -cm-long spurs at $\approx 11$-week intervals, beginning 17 Feb. 1989 for the four treatments. Fresh and dry weights were obtained for each sampling date.

Tissue mineral analysis. Nutritional analysis of the buds was performed for each sampling date. A modified Kjeldahl method (Schuman et al., 1973) was used for total $\mathrm{N}$ analysis. Inductively coupled plasma spectrometry (Isaac and Johnson, 1985) measured $\mathrm{P}, \mathrm{K}, \mathrm{Ca}$, and $\mathrm{B}$.

\section{Ovule longevity determination}

Field experiment. Flower buds were emasculated before bloom to prevent self-pollination and covered with cheesecloth bags to prevent pollination by bees. Ten flowers, excised from the apical position of a spur $(\approx 2 \mathrm{~cm})$ for each treatment, were sampled every 2 days from full bloom until 20 days after full bloom (DAFB). The number of open flowers per limb were counted periodically and full bloom was considered as the time when at least $80 \%$ of the flowers were open. The full-bloom dates for the first year of study were 11, 12, 12, and 13 Apr. 1989 for 'Brooks', 'Brooks' + ethephon, 'Italian', and 'Italian' + ethephon trees, respectively. In the second season, the recorded fullbloom dates for the same treatments were 30 Mar. and 3, 1, and 10 Apr. 1990. Five flowers of each treatment were sampled every 3 days from full bloom until 15 DAFB. Samples were fixed in 5 formaldehyde :5 propionic acid :90 95\% ethanol (FAP) (by volume) until observations were made.

Flowers. were removed from the FAP solution, washed in distilled water for 3.0 rein, soaked in $1 \%$ sodium bicarbonate for $1 \mathrm{~h}$, and rinsed three times in distilled water. Pistil and ovary samples were softened by autoclaving in $1 \%$ sodium sulfite for 2 min. Pistils were excised, ovaries were split longitudinally, and the two ovules were removed with the aid of fine forceps under a light microscope. Ovules were then mounted on slides by direct squash in $0.5 \%(\mathrm{w} / \mathrm{v})$ aqueous aniline blue (C.I. 42755; Baker Chemical Co., Phillipsburg, N. J.) in 0.15 m potassium phosphate buffer. Slides were observed under a Carl Zeiss (Oberkochen, Germany) universal fluorescence microscope equipped for epi-illumination with near-ultraviolet excitation (Crisosto, 1987; Pimienta et al., 1983).

Ovule longevity was tested by differential intensity of ovule fluorescence after staining with aniline blue. Strong fluorescence of the ovule at the chalazal end indicates nonviable ovules (Polito and Pimienta, 1982; Stosser and Anvari, 1982). Each flower was rated for the number of viable (nonfluorescing) ovules per ovary. The mean number of viable ovules per flower was calculated for the 10 flowers per treatment on each sampling date.

Growth chamber experiment. In 1990, to determine the effect of temperature and ethephon treatment on ovule longevity, three replicates of 20 twigs each, up to $15 \mathrm{~cm}$ long, were cut from flowering trees of the two genotypes and placed in shallow trays in moist florist's foam (Oasis Floral Products, Smithers-Oasis, France) (Jefferies et al., 1982). Three flowers per twig were emasculated to prevent self-pollination. The pots were then transferred to controlled environment chambers. Conditions were $5,10,15$, and $20 \mathrm{C}$, with a 16 -h light/8-h dark period. A Murashige and Skoog basal salt mixture (M5524; Sigma Chemical, St. Louis) solution was added to the trays to fulfill nutritional requirements. Distilled water was subsequently added periodically to avoid moisture loss. Samples of 10 flowers were taken every 2 days for at least $18 \mathrm{DAFB}$, depending on the temper- ature. The flowers were fixed in FAP solution and prepared as above.

Statistical analysis. Both experiments were conducted as a completely randomized design. Data for the tissue mineral analysis and growth measurements were analyzed using two models. The data for fresh weight (FW), dry weight (DW), and $\mathrm{N}$ and $\mathrm{P}$ content were fitted to a nonlinear analysis of covariance, exponential growth model: $\quad: Y_{\mathrm{ij}}=\alpha_{\mathrm{i}} \exp \left(\beta_{\mathrm{i}} \times \mathrm{day}_{\mathrm{j}}\right)+\tau_{\mathrm{i}}+\epsilon_{\mathrm{ijt}}$; $\mathrm{i}=1-4, \mathrm{j}=1-8$. The $\mathrm{ij}^{\mathrm{th}^{\mathrm{j}}}$ response is denoted $\mathrm{Y}_{\mathrm{ij}}$, the $\mathrm{j}^{\mathrm{j}}$ regressor is denoted day, and day $1=0$ corresponds to 17 Feb. The index $i=1,2,3,4$ corresponds to the treatments 'Italian' (I), 'Italian' + ethephon (I + E), 'Brooks' (B), and 'Brooks' + ethephon $(\mathrm{B}+\mathrm{E})$, respectively. The random error terms are assumed to be independent and identically distributed with a mean of zero. The 12 parameters for $\alpha_{\mathrm{i}}$, and $\beta_{\mathrm{i}}$, and $\tau_{\mathrm{i}}$ were estimated by nonlinear least squares. The parameters, $\alpha$, $\beta$, and $\tau$ do not have a simple geometrical and biological interpretation. Consequently, instead of testing whether each individual parameter differed among treatments, we decided to test jointly whether all three parameters differed among treatments. This procedure corresponds to testing whether the regression functions coincide. The hypotheses of coincident responses among treatments were tested with likelihood ratio, approximate $\mathrm{F}$ tests (Seber and Wild, 1989).

The responses of $\mathrm{P}$ and $\mathrm{Ca}$ were fitted to the linear analysis of covariance model $\quad Y_{i j}=\alpha_{i}+\beta_{i} \times$ day $_{j}+\epsilon_{i j} ; i=1-4$, $\mathrm{j}=1-8$. The notation is the same as in the exponential growth model. The eight parameters for $\alpha_{i}$ and $\beta_{i}$ were estimated by least squares. We again tested whether the regression lines were coincident.

For B, actual B content, rather than B concentration, for a sample of 100 buds was obtained. Ovule longevity data for the field experiment, as well as B content of buds, were analyzed by using a general linear model procedure in SAS (SAS Institute, 1987). Differences among treatments were tested by using orthogonal contrasts.

Data from the growth chamber experiments were combined for a response surface regression analysis. Separate regressions were performed for each cultivar/ethephon treatment/temperature combination for a total of four analyses. The regression model used was a complete quadratic response surface model of the form: $\quad Y=\beta_{0}+\beta_{1} X_{1}+\beta_{11} X_{1}{ }^{2}+\beta_{2} X_{2}+\beta_{22} X_{2}^{2}+$ $\beta_{12} X_{1} X_{2}+\beta_{1122} X_{1}^{2} X_{2}^{2}$, , where $Y=$ number of viable ovules, $X_{1}=$ temperature; and ${ }^{-} X_{2}^{\prime}=$ DAFB. Components were deleted from the model if their parameter estimate $(\beta)$ was not significant $(\alpha=0.05)$. If a component increased the mean square error $\left(\delta^{2}\right) \quad$ or if its deletion did not decrease the $R^{2}$ of the model, it was also deleted. Results are presented as graphs of the predicted values from the models.

\section{Results}

Growth rate and mineral content of buds. Ethephon-treated flower buds of both cultivars had different growth rates when compared to their controls. Tests of hypothesis and probability levels for the equations fitted to each particular treatment (Table 1) show the significance of these differences. The model for FW and DW has an $R^{2}=0.989$ and 0.986 , respectively. In both cases, the ethephon treatment resulted in a lower rate of bud growth (Fig. 1). 'Brooks' flower buds showed a higher accumulation of FW and DW than 'Italian' buds.

The model for $\mathrm{N}$ has an $R^{2}=0.982$ (Table 1); however, there were no differences in $\mathrm{N}$ concentration between the treatments (Fig. 1). For K, the model has an $R^{2}=0.988$ (Table 1). 
Table 1. Tests of hypothesis and probability levels for the exponential growth model fitted to the responses for FW, $\mathrm{DW}$, and concentration of $\mathrm{N}$ and $\mathrm{K}$, and the simple linear model fitted to the responses for $\mathrm{P}$ and $\mathrm{Ca}$ concentration for nontreated and ethephon-treated 'Italian' and 'Brooks' flower buds.'

\begin{tabular}{|c|c|c|c|c|c|c|c|c|c|c|c|c|}
\hline \multirow[b]{3}{*}{ Null hypothesis } & \multicolumn{12}{|c|}{ Response variable } \\
\hline & \multicolumn{2}{|c|}{ FW } & \multicolumn{2}{|c|}{ DW } & \multicolumn{2}{|r|}{$\mathrm{N}$} & \multicolumn{2}{|r|}{$\mathrm{K}$} & \multicolumn{2}{|r|}{$\mathbf{P}$} & \multicolumn{2}{|r|}{$\mathrm{Ca}$} \\
\hline & $\mathbf{F}$ & $P$ value & $\mathrm{F}$ & $P$ value & $\mathrm{F}$ & $P$ value & $\mathbf{F}$ & $P$ value & $\mathrm{F}$ & $P$ value & $\mathrm{F}$ & $P$ value \\
\hline $\begin{array}{l}\mathrm{B}, \mathrm{B}+\mathrm{E}, \mathrm{I}, \text { and } \mathrm{I}+\mathrm{E}^{\mathrm{y}} \\
\text { all coincide }\end{array}$ & 21.60 & 0.000 & 15.79 & 0.000 & 1.21 & 0.341 & 4.64 & 0.002 & 2.65 & 0.041 & 3.34 & 0.015 \\
\hline$B$ and $B+E$ coincide & 10.42 & 0.000 & 7.77 & 0.001 & -- & -- & 2.90 & 0.060 & 0.50 & 0.612 & 1.27 & 0.300 \\
\hline $\mathrm{B}$ and I coincide & 25.42 & 0.000 & 22.49 & 0.000 & --- & --- & 2.13 & 0.129 & 1.07 & 0.360 & 1.09 & 0.353 \\
\hline $\mathrm{B}$ and $\mathrm{I}+\mathrm{E}$ coincide & 60.33 & 0.000 & 41.04 & 0.000 & --- & --- & 4.14 & 0.020 & 2.42 & 0.110 & 9.01 & 0.001 \\
\hline $\mathrm{B}+\mathrm{E}$ and I coincide & 3.60 & 0.031 & 4.65 & 0.013 & --- & --- & 7.69 & 0.001 & 0.17 & 0.847 & 0.49 & 0.616 \\
\hline $\mathrm{B}+\overline{\mathrm{E}}$ and $\mathrm{I}+\mathrm{E}$ coincide & 20.89 & 0.000 & 14.85 & 0.000 & -- & -- & 9.92 & 0.000 & 5.02 & 0.015 & 3.61 & 0.043 \\
\hline $\mathrm{I}$ and $\mathrm{I}+\mathrm{E}$ coincide & 9.09 & 0.001 & 4.01 & 0.022 & --- & --- & 1.16 & 0.348 & 6.70 & 0.005 & 4.58 & 0.021 \\
\hline
\end{tabular}

${ }^{2}$ Based on data obtained from three replicates of 100 terminal buds each.

${ }^{\mathrm{y}} \mathrm{B}=$ 'Brooks'; $\mathrm{B}+\mathrm{E}=$ 'Brooks' + ethephon; $\mathrm{I}$ = 'Italian'; $\mathrm{I}+\mathrm{E}$ = 'Italian' + ethephon.


Fig. 1. Predicted FW, DW, N, K, P, and Ca for nontreated and ethephon-treated flower buds excised from 'Italian' and 'Brooks' prune trees. Day $50=$ full bloom.

For both genotypes, there were no significant differences between the ethephon treatment and the controls (Fig. 1). However, in comparisons between ethephon-treated 'Italian' and 'Brooks' flower buds, a significant increase in $\mathrm{K}$ concentration in the 'Brooks' flower buds was observed.

The tests of hypothesis and probability levels for $\mathrm{P}$ and $\mathrm{Ca}$ appear in Table 1. There was no effect of ethephon application for $\mathrm{P}$ responses $\left(R^{2}=0.884\right)$ of 'Brooks' flower buds. Ethephon-treated 'Italian' buds had lower P concentrations than the control (Fig. 1). The Ca response $\left(R^{2}=0.965\right)$ was similar to that for P. Ethephon treatment had no effect on 'Brooks'. Calcium concentration was significantly higher in 'Italian' buds treated with ethephon than in nontreated buds (Fig. 1).

There was no difference in B content per bud between the ethephon treatment and the controls during the first three dates of sampling (Table 2). From 10 Mar., 'Italian' + ethephon had significantly higher B content than the control treatment. The $\mathrm{B}$ content of treated and nontreated 'Brooks' flower buds were 
Table 2. The effect of fall-applied ethephon on B content (in milligrams) of 'Brooks' and 'Italian' prune flower buds sampled from 50 days before bloom until just before full bloom. ${ }^{2}$

\begin{tabular}{|c|c|c|c|c|c|c|c|c|}
\hline \multirow[b]{2}{*}{ Treatment } & \multicolumn{8}{|c|}{ Sample date } \\
\hline & 17 Feb. & 24 Feb. & 3 Mar. & 10 Mar. & 18 Mar. & 25 Mar. & 31 Mar. & $7 \mathrm{Apr}$. \\
\hline$\overline{\mathrm{I}^{\mathrm{y}}}$ & 11.13 & 12.17 & 14.23 & 12.60 & 15.20 & 14.87 & 20.10 & 45.66 \\
\hline$i+E$ & 12.43 & 13.83 & 15.13 & 17.53 & 20.40 & 21.60 & 27.07 & 48.60 \\
\hline B & 10.20 & 10.37 & 12.00 & 16.47 & 15.40 & 15.10 & 31.13 & 54.43 \\
\hline $\begin{array}{l}B+E \\
\text { Significance }\end{array}$ & 8.76 & 9.87 & 11.03 & 13.13 & 16.50 & 16.10 & 30.77 & 64.00 \\
\hline \multicolumn{9}{|l|}{ Contrasts } \\
\hline I vs. I + E & NS & NS & NS & $* *$ & * & $* *$ & $* *$ & $* *$ \\
\hline$B$ vs. $B+E$ & NS & NS & NS & $* *$ & $*$ & $* * *$ & $*$ & $*$ \\
\hline $\bar{I}+(I+E)$ & NS & NS & NS & $*$ & NS & NS & NS & $*$ \\
\hline vs. $B+(B+E)$ & NS & NS & NS & NS & NS & NS & $* *$ & $* *$ \\
\hline
\end{tabular}

${ }^{2}$ Average $\mathrm{B}$ content of three samples (100 buds each) from 10 trees.

${ }^{\mathrm{y}} \mathrm{B}=$ 'Brooks'; $\mathrm{B}+\mathrm{E}=$ 'Brooks' + ethephon; I = 'Italian'; I + E = 'Italian' + ethephon. Ns, *, **, ***Nonsignificant or significant at $P=0.05,0.01$, or 0.001 , respectively.

only different at two sampling dates, 10 Mar. and 7 Apr. When comparing the overall $\mathrm{B}$ content for each cultivar, it was higher in 'Brooks' only at the last two sampling dates.

\section{Ovule longevity}

Field experiment. In 1989, senescence clearly progressed differently in the two cultivars in the field. During the first 8 days of study, nontreated and ethephon-treated 'Italian' flowers had fewer viable ovules than flowers of treated or nontreated 'Brooks' (Table 3). After this date, this difference became nonsignificant until the last two sampling dates. The rate of ovule death of 'Brooks' flowers was generally the same for the ethephon treatment and the control. There was no difference in any of the sampling dates, except 8 DAFB (Table 3). For 'Italian', flowers started with fewer viable ovules until 8 DAFB, when there was no difference between the ethephon-treated and control flowers. After that date, ethephon-treated flowers showed significantly more viable ovules than nontreated ones.

Some ovules of 'Italian' flowers had already died by anthesis, when only $80 \%$ of the flowers had two viable ovules (Fig. 2). After 6 days, $20 \%$ of the flowers had two dead ovules and another $20 \%$ had only one viable ovule. By 11 DAFB, only $60 \%$ of the flowers had viable ovules. Ovule senescence continued until 20 DAFB, when $40 \%$ of the flowers had only one viable ovule. The rest had no viable ovules.

The ovules of 'Italian' flowers excised from ethephon-treated trees displayed a clearly different rate of senescence than nontreated 'Italian' flowers. At full bloom, $20 \%$ of the flowers of treated trees had two viable ovules, but the rest of the flowers had only one. By 11 DAFB, $90 \%$ of the flowers had viable ovules. By 20 DAFB, $80 \%$ of the flowers had at least one ovule that remained viable.

For 'Brooks', 100\% of the flowers had two viable ovules at O DAFB (Fig. 2). By 8 DAFB, $70 \%$ of the flowers had two viable ovules, and the rest had at least one. Only $30 \%$ of the flowers had two viable ovules at 11 DAFB, but in the remaining samples, at least one ovule remained viable. At the last sampling date (20 DAFB), only $10 \%$ of the flowers were without viable ovules, $10 \%$ had two viable ovules, and the remaining $80 \%$ had at least one nonsenescing ovule per ovary.

Ethephon treatment did not seem to affect the pattern of ovule longevity in 'Brooks'. Only $80 \%$ of ethephon-treated flowers had two viable ovules at full bloom (Fig. 2). The number of viable ovules remained the same until 6 DAFB. By 11 DAFB, $80 \%$ of the flowers had at least one viable ovule, this being the case for the next 9 days of study.

Similar ovule longevity results were observed in 1990, with the exception of ethephon-treated 'Brooks' flowers, which lived slightly longer than nontreated flowers (data not shown). 'Italian' ovules from control trees senesced faster than ovules from ethephon-treated 'Italian' flowers. Again, 'Brooks' flowers had viable ovules for a longer period than 'Italian' flowers.

Table 3. Number of viable ovules in 'Brooks' and 'Italian' prune flowers treated with or without ethephon from full bloom until 20 DAFB under field conditions in $1989 .{ }^{2}$

\begin{tabular}{|c|c|c|c|c|c|c|c|c|c|}
\hline \multirow[b]{2}{*}{ Treatment } & \multicolumn{9}{|c|}{ DAFB } \\
\hline & 0 & 4 & 6 & 8 & 11 & 13 & 15 & 17 & 20 \\
\hline$\overline{I^{y}}$ & 1.8 & 1.5 & 1.4 & 1.0 & 0.8 & 0.8 & 1.0 & 0.6 & 0.4 \\
\hline$I+E$ & 1.2 & 1.2 & 1.1 & 1.1 & 1.1 & 1.0 & 0.9 & 1.0 & 0.8 \\
\hline B & 2.0 & 1.8 & 1.8 & 1.7 & 1.2 & 1.1 & 1.2 & 1.1 & 1.0 \\
\hline$B+E$ & 1.8 & 1.8 & 1.8 & 1.5 & 1.2 & 1.2 & 1.1 & 1.1 & 1.2 \\
\hline Significance & $* * *$ & $*$ & $*$ & $*$ & NS & NS & NS & $*$ & $* *$ \\
\hline \multicolumn{10}{|l|}{ Contrasts } \\
\hline I vs. I + E & $* * *$ & $*$ & $*$ & NS & $*$ & $*$ & NS & $* *$ & $* *$ \\
\hline $\begin{array}{l}\text { B vs. } B+E \\
I+(I+E)\end{array}$ & NS & NS & NS & $*$ & NS & NS & NS & NS & NS \\
\hline vs. $B+(B+E)$ & $* *$ & * & $* *$ & $* *$ & NS & NS & NS & * & ** \\
\hline
\end{tabular}



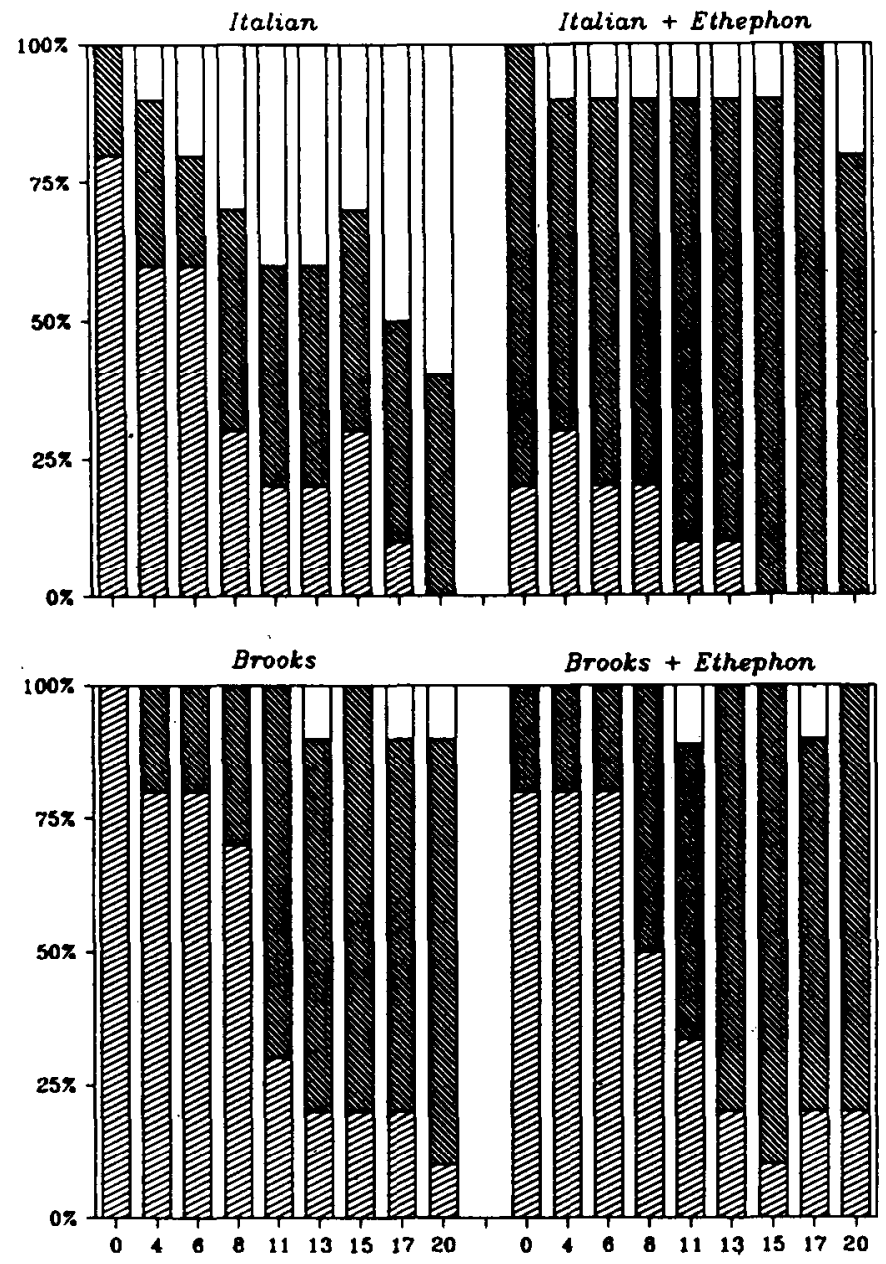

Days after full bloom

Fig. 2. Frequency, distribution of the number of flowers with two ( $\mathbb{Z}$ ), one ( $)$, or no ( $\square$ ), viable ovules from full bloom until 20 DAFB excised from nontreated and ethephon-treated 'Italian' and 'Brooks' prune trees.

Growth chamber experiment. The predicted number of viable ovules in 'Italian' flower buds at 0 DAFB was fewer than two, indicating that ovular senescence had already occurred before bloom. This was not so for 'Brooks', where two viable ovules were present at full bloom in all flowers (Table 4, Fig. 3).

Across' all temperature regimes, 'Italian' had fewer viable ovules than 'Brooks'. At 5C, the rate of ovule death was similar for both cultivars. The difference between the predicted average number of ovules across days is explained by the initial lower ovule viability of 'Italian'. As temperature increased, ovule senescence was faster in 'Italian' than in 'Brooks'. At 15C, only one ovule per flower remained viable by 8 DAFB for 'Italian'. For 'Brooks', higher temperatures also resulted in a more rapid decrease in ovule longevity over time, but at a lower rate than for 'Italian'. Total ovule senescence for some 'Italian' flowers had already occurred by 2 DAFB at 20C. For 'Brooks' flowers at the same temperature, senescence of both ovules began 4 days later (6 DAFB).

For 'Brooks', flowers from treated and nontreated spurs had the same number of viable ovules at anthesis (Fig. 3). The surface response for the ethephon-treated buds was different than that of the nontreated control buds. At low temperatures, the rate of ovule senescence was similar in both cases and a clear difference only started to appear between 15 and 20C. At $20 \mathrm{C}$, ovule longevity was slightly enhanced by ethephon treatment. By 18 DAFB, the ethephon-treated flowers had more viable ovules than the control.

Fall-applied ethephon reduced the rate of ovule death in both cultivars (Fig. 3). For 'Italian', ethephon application translated into fewer viable ovules at anthesis. However, those ovules remained viable for a longer period. Ovule longevity was enhanced, but this effect also depended on temperature. This interaction was particularly important at 20C. Without ethephon, some flowers were already lacking viable ovules at 2 DAFB. However, when treated with ethephon, at least one viable ovule was present until $10 \mathrm{DAFB}$. Also, at $15 \mathrm{C}$, more ovules per flower remained viable in the ethephon-treated flowers. At $5 \mathrm{C}$, there appeared to be little difference between the ethephon treatment and the control.

\section{Discussion}

Flower buds treated with ethephon grew more slowly than the controls during the winter. This difference was maintained. during the period of flower bud swell in the spring. There was a considerable difference in terms of FW and DW. According to Gianfagna (1989), pistil length was only $80 \%$, and the length of the flower buds was $90 \%$ of nontreated 'Cresthaven' peach buds within 1 month of the ethephon application. In our case, buds from the ethephon-treated trees were $20 \%$ smaller than nontreated buds. This difference might be explained by reduced cell division in the ethephon-treated buds (Gianfagna, 1989). Apelbaum and Burg (1972) have shown that ethylene inhibits cell division in the plumular hook of pea. Inhibition of the growth of dormant buds by ethephon suggests that ethylene released in the tissues may inhibit cell division during the later phases of flower differentiation in the autumn (Crisosto et al.,

Table 4. Regression equations, coefficients of determination $\left(\mathrm{Z} ?^{*}\right)$, and model significance probabilities $(P>F)$ of the number of viable ovules for nontreated and ethephon-treated 'Italian' and 'Brooks' prune flower buds held at 5, 10, 15, and 20C.

\begin{tabular}{|c|c|c|c|}
\hline Treatment & Equation & $R^{2}$ & $P>\mathrm{F}$ \\
\hline$\overline{\mathrm{I}^{2}}$ & $\begin{aligned} Y= & 1.2872+0.1233 \mathrm{X}_{1}+0.0831 \mathrm{X}_{2}-0.0053 \mathrm{X}_{1}^{2}- \\
& 0.0029 \mathrm{X}_{2}^{2}-0.0143 \mathrm{X}_{1} \mathrm{X}_{2}+0.00002315 \mathrm{X}_{1}^{2} \mathrm{X}_{2}^{2}\end{aligned}$ & 0.51 & 0.0001 \\
\hline $\mathrm{I}+\mathrm{E}$ & $Y=1.3450+0.0471 X_{1}-0.0024 X_{1}^{2}-0.0034 X_{1} X_{2}$ & 0.31 & 0.0001 \\
\hline B & $\begin{aligned} \mathrm{Y}= & 1.5679+0.0924 \mathrm{X}_{1}+0.0635 \mathrm{X}_{2}-0.0039 \mathrm{X}_{1}^{2}- \\
& 0.0015 \mathrm{X}_{2}^{2}-0.0105 \mathrm{X}_{1} \mathrm{X}_{2}+0.00001546 \mathrm{X}_{1}^{2} \mathrm{X}_{2}^{2}\end{aligned}$ & 0.41 & 0.0001 \\
\hline $\mathrm{B}+\mathrm{E}$ & $\mathrm{Y}=1.9345-0.0038 \mathrm{X}_{1}-0.0011 \mathrm{X}_{2}-0.0034 \mathrm{X}_{1} \mathrm{X}_{2}$ & 0.25 & 0.0001 \\
\hline
\end{tabular}



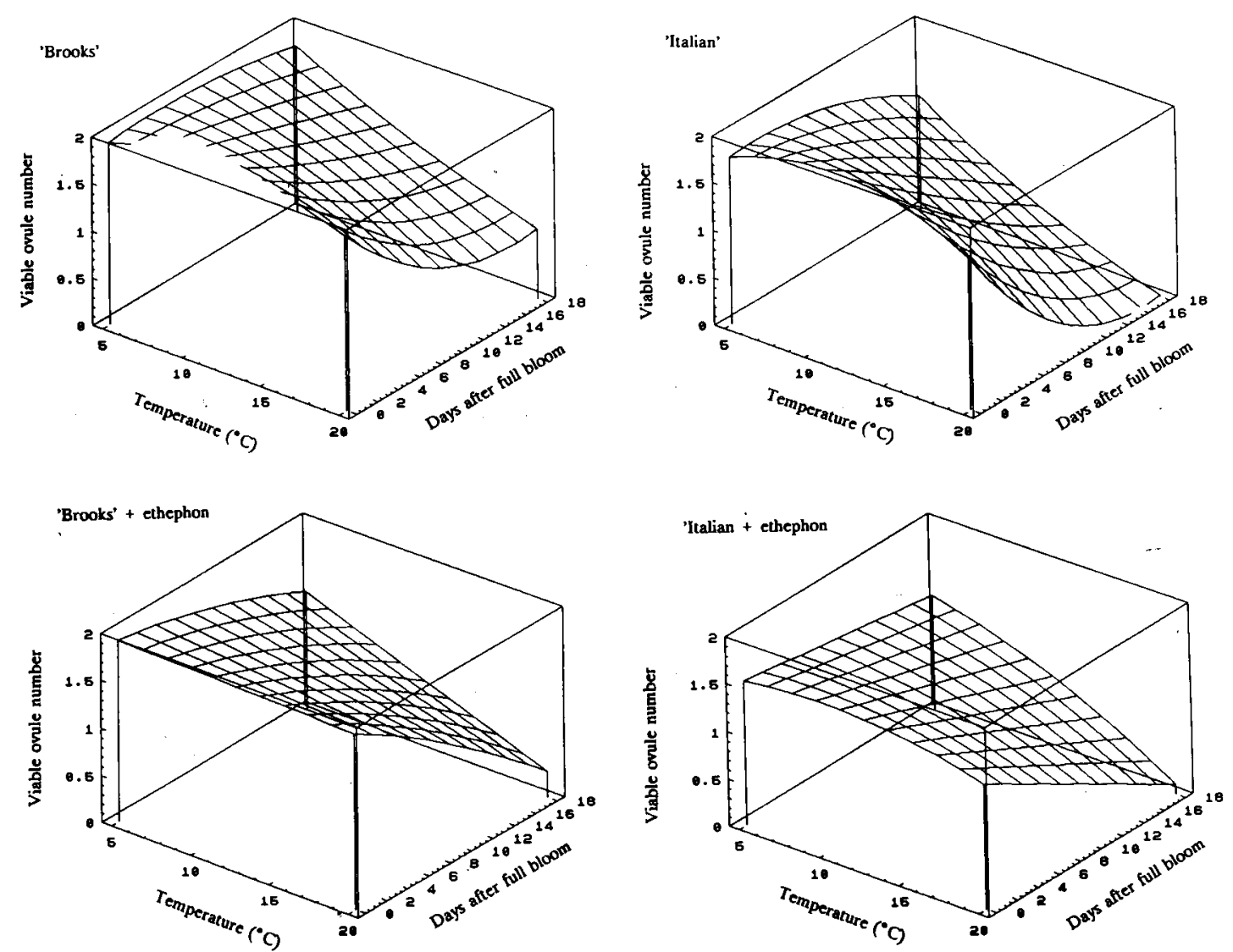

Fig. 3. Predicted number of viable ovules derived from equations in Table 4 for nontreated and fall ethephon-treated (500 mg.liter $\left.{ }^{-1}\right)$ flowers excised from 'Italian' and 'Brooks' prune trees and held for 18 DAFB at 5, 10, 15, and 20C.

1989). Delayed differentiation of flower primordia could result in a delay in flower development the following spring.

As the process of flower bud development is a complex phenomenon under both genetic and environmental control, it may be directly and indirectly related to a number of organic and inorganic nutritional factors. However, the literature does not provide much evidence for categorizing the essential elements in this regard. In addition, there is no report in the literature regarding the effect of ethephon application on mineral element content of flower buds. Our results show that $\mathrm{N}$ and $\mathrm{K}$ concentrations in flower bud tissue were not changed by ethephon application. 'Jonathan' apple trees deficient in P show delayed bud burst and retarded development of fewer vegetative and floral meristems (Taylor and Goubran, 1975). Our results agree with this report to the extent that the 'Italian' flower buds had a lower P concentration with the ethephon application and bloomed later.

The higher concentration of $\mathrm{Ca}$ as a result of the ethephon application could be associated with delayed growth rather than increased movement of $\mathrm{Ca}^{+2}$ into the buds. The vascular bundles of the ethephon-treated prune buds developed more slowly than those of nontreated buds (Sun et al., 1990). Calcium has relatively low mobility in the plant and is translocated mainly acropetally via xylem sap with the transpiration stream (Mengel and Kirby, 1982). As was the case for ethephon-treated buds, where growth was delayed and transpiration rates were most likely low, it is improbable that additional $\mathrm{Ca}$ was moved into buds. What we observed was most likely a dilution effect in the case of the nontreated control as growth started early and before the spring transport of CA into the buds.
Boron levels also were higher in ethephon-treated buds of 'Italian' than in the control. Dilution cannot account for the lower levels of B in the nontreated controls, as B was expressed as total content per 100 buds. Hanson (1984) stated that remobilization of B from 'Italian' prune branches was more limited than that of other elements. In intact trees, B accumulated in buds more slowly before bud swelling. However, B accumulates rapidly as buds accumulate dry matter from swelling to bloom. Hanson and Breen (1985b) explained these results by suggesting that xylem in the axis of flower buds became functional only when buds began to swell. However, the putative xylem-supplied B accounted for only $26 \%$ of that B entering buds. In the same report, they reasoned that since buds showed limited dry matter accumulation at this time, they were weak carbon sinks and suggested that symplastic flow, or xylem transport, to buds would also be limited. Ethephon may have altered the intrinsic physiology of the buds and allowed enhanced B movement to buds in the spring.

Longer ovule viability of 'Brooks' flowers, compared to 'Italian', was observed under both field and growth chamber conditions. Ethephon application did not change this difference markedly. 'Brooks' flowers seem to fit Williams' (1965) description of a "strong" flower; these flowers were larger and bloomed earlier. Ten percent of 'Brooks' flowers were "strong" enough to maintain two viable ovules until 20 DAFB. At this time, senescence of both ovules was observed in only $10 \%$ of the flowers; the remaining $90 \%$ still had one viable ovule. 'Italian' flowers can be classified as "weak" blossoms according to the criteria outlined by Williams (1965). Some ovule senescence was already apparent at the time of bloom. The ovules 
of 'Italian' flowers also senesced at a faster rate than those of 'Brooks'. Ethephon-treated flowers at bloom had fewer viable ovules, but they showed a delayed senescence and, in practical terms, might have improved the chance of fertilization.

Efforts to prolong ovule longevity have been successful in apple by improving cultural conditions (Dorsey, 1929; Williams, 1963, 1965). Williams (1965) found that summer N, application provided optimal nutritional conditions at the time of flower initiation, which greatly increased the proportion of strong flowers. Kliewer (1977) stated that grape (Vitis vinifera L.) ovule fertility may be markedly affected by a supply of organic nutrients to the ovules. Perhaps, the lower fruit set observed in the 'Italian' genotype can be explained by a limited supply of nutrients to the flower buds (Thompson and Liu, 1973; Hanson and Breen,. 1985a). If one of the ovules is senescent, as when ethephon-treated, the other ovule may compete better for a "limited" supply of nutrients to the flower buds. In addition, increased amounts of $\mathrm{B}$ and $\mathrm{Ca}$ in the ethephon-treated buds may enhance ovule longevity.

The results clearly illustrated that ovule senescence was influenced by temperature. Ovule senescence was very rapid at the higher temperatures we used. However, genotype and ethephon treatment interacted with temperature. Fruit set in grape was much better at $25 \mathrm{C}$ than at 35 or $40 \mathrm{C}$ (Ewart and Kliewer, 1977; Kliewer, 1977). They indicated that ovules degenerated earlier as temperature increased, relating this to an insufficient supply of organic nutrients to the ovules. Tomato (Lycopersicon esculentum Mill.) ovules were affected by high temperatures more drastically than was pollen (El-Ahmadisand Stevens, 1979). Ovule viability was reduced in all cases by high temperatures, but cultivars differed significantly in this respect. Levy at al. (1978) found that tomato male gamete viability was affected more at high temperature than that of female gametes. However, the degree of the temperature effect between the male or female gamete was found to be genotype-dependent. In our experiments, ovule longevity of 'Brooks' seemed to be less dependent on temperature than that of 'Italian'. This independence may be associated with the capacity of 'Brooks' to consistently set a crop. The effect of ethephon. in preventing ovule senescence in 'Brooks' flowers was less marked and occurred only at high temperatures. Perhaps, as a result of the tendency of 'Brooks' to produce strong ovules, these ovules have a higher temperature stress threshold than those of 'Italian'.

Flower buds from 'Italian' trees were smaller and had a lower concentration and content of $\mathrm{Ca}$ and $\mathrm{B}$, respectively, when compared to 'Brooks' flower buds. Ovule longevity was shorter in 'Italian' flowers. Since the 'Italian' genotype apparently has a "weaker" flower genotype when compared to 'Brooks', cultural practices that ameliorate this weaker condition have the potential to enhance ovule longevity. As 'Brooks' flowers already have the tendency to produce strong flowers, increasing ovule longevity may not be possible.

\section{Literature Cited}

Apelbaum, A. and S.P. Burg. 1972. Effect of ethylene on cell division and deoxyribonucleic acid synthesis in Pisum sativum. Plant Physiol. 50:117-124.

Coston, D. C., G.W. Krewer, T.E. Elkner, J.G. Williamson, and E.T. Sims, Jr. 1985. Chemical treatments for bloom delay in peach. J. Amer. Soc. Hort. Sci. 110:874-877.

Crisosto, C.H. 1987. The effect of the ethylene manipulation of flower bud development of Prunus domestics, Prunus persica, and of Pyrus communis ovule senescence. PhD Diss., Oregon State Univ., Corvallis.
Crisosto, C. H., P.B. Lombard, and L.H. Fuchigami. 1989. Fall ethephon delays bloom in 'Redhaven' peach by delaying flower differentiation and development during dormancy. J. Amer. Soc. Hort. Sci. 114:881-884.

Crisosto, C. H., A.N. Miller, P.B. Lombard, and S. Robbins. 1990. Effect of fall ethephon applications on bloom delay, flowering and fruiting of peach and prune. HortScience 25:426-428.

Dennis, F.G. 1976. Trials of ethephon and other growth regulators for delaying bloom in tree fruits. J. Amer. Soc. Hort. Sci. 101:241245.

Dorsey, N.J. 1929. The relation between embryo-sac development and tree set of fruit in apple. Proc. Amer. Soc. Hort. Sci. 26:56-61.

I)urner, E. F., T.J. Gianfagna, F.X. Rooney, G.S. Teiger, M.J. Seiler, and M.J. Cantarella. 1990. Harvest date and size distribution of peach fruit are altered with fall-applied ethephon. HortScience 25:911913.

Eaton, G.W. 1959. A study of the megagametophyte in Prunus avium and its relation to fruit setting. Can. J. Plant Sci. 39:466-467.

E1-Ahmadi, A.B. and M.A. Stevens. 1979. Reproductive responses of heat tolerant tomatoes to high temperatures. J. Amer. Soc. Hort. Sci. 104:686-691.

Ewart, A. and W.M. Kliewer. 1977. Effects of controlled day and night temperatures and nitrogen on fruit set, ovule fertility, and fruit composition of several wine grape cultivars. Amer. J. Enol. Viticult. 28:88-95.

Gianfagna, T. J., R. Marini, and S. Rachmiel. 1986. Effect of ethephon and GA on time of flowering of peach. HortScience 21:69-70.

Gianfagna, T.J. 1989. Chemical control with ethephon of bud dormancy, cold hardiness and time of bloom in peach. PGRSA Quarterly 17:39-47.

Hanson, E.J. 1984. Boron nutrition and fruit set of 'Italian' prune. PhD Diss., Oregon State Univ., Corvallis.

Hanson, E.J. and P.J. Breen: 1985a. Effect of fall boron sprays and environmental factors on fruit set and boron accumulation in 'Italian' prune flowers. J. Amer. Soc. Hort. Sci. 110:747-748.

Hanson, E.J. and P.J. Breen. 1985b. Xylem differentiation and boron accumulation in 'Italian' prune flower buds. J. Amer. Soc. Hort. Sci. 110:556-570.

Isaac, R.A. and W.C. Johnson. 1985. Elemental analysis of plant tissue by plasma emission spectroscopy Collaborative study. J. Assn. Anal. Chem. 68:449-505.

Jaumien, F. 1968. The causes of poor bearing of pear trees of the variety 'Doyenne du cornice'. Acts Agrobotanica 21:110-114.

Jefferies, C. J., P. Brain, K.G. Scott, and A.R. Belcher. 1982. Experimental systems and a mathematical model for studying temperature effect on pollen tube growth and fertilization in plum. Plant, Cell \& Environ. 5:231-236.

Keulemans, J. 1984. The effect of temperature on pollen tube growth and fruit set on plum trees. Acta Hort. 149:95-101.

Kliewer, W .M. 1977. Effect on high temperatures during the bloom set period on fruit set, ovule fertility and berry growth of several grape cultivars. Amer. J. Enol. Viticult. 28:215-222.

Levy, A., H.O. Rabimovitch, and N. Keder. 1978. Morphological and physiological characters affecting flower drop and fruit set of tomatoes at high temperature. Euphytica 27:211-218.

Mengel, K. and E.A. Kirkby. 1982. Principles of plant nutrition. 3rd ed. Intl. Potash Inst., Bern, Switzerland p. 437460.

Pimienta, A. E., V.S. Polito, and D.E. Kester. 1983. Pollen tube growth in cross- and self-pollinated 'Nonpareil' almond. J. Amer. Soc. Hort. Sci. 108:643-647.

Polito, V.S. and E. Pimienta. 1982. A rapid and accurate fluorescence method using ovule whole mounts to assess fertilization in plants. Mikroskopie 39:32-34.

Proebsting, E.L., Jr., and H.H. Mills. 1973. Bloom delay and frost survival in ethephon treated sweet cherry. HortScience 8:46-47.

SAS Institute. 1987. SAS/STAT guide for personal computers, version 6 ed. SAS Institute, Inc., Cary, N.C.

Schuman, G. E., A.M. Stanley, and D. Knudson. 1973. Automated 
total nitrogen analysis of soil and plant samples. Soil Sci. Amer. Proc. 37:480-481

Seber, G.A.F. and S.J. Wild. 1989. Nonlinear regression. Wiley, New York.

Sun, X., A.N. Miller, M. Faust, and W. Potts. 1991. Effect of fall ethephon application on flower bud development in 'Italian' prune. Scientia Hort. 45:199-207.

Stosser, R. and S.F. Anvari. 1982. On the senescence of ovule in cherries. Scientia Hort. 16:28-29.

Taylor, B.K. and F.H. Goubran. 1975. The phosphorus nutrition of the apple tree. I. Influence of rate of application of superphosphate on the performance of young trees. Austral. J. Agr. Res. 26:843853. “

Thompson, M.M. and L.J. Liu.. 1973. Temperature, fruit set and em- bryo sac development in 'Italian' prune. J. Amer. Soc. Hort. Sci. 55:193-197.

Webster, A.D. 1986. Delaying flowering and improving the yield of plum cultivars with ethephon and gibberellic acid sprays. Acta. Hort. 179:171-172.

Williams, R.R. 1963. The effect of nitrogen on the self-fruitfulness of certain varieties of cider apples. J. Hort. Sci. 38:52-60.

Williams, R.R. 1965. The effect of summer nitrogen applications on the quality of apple blossoms. J. Hort. Sci. 40:31-41.

Williams, R.R. 1966. The effective pollination period for some apple and pear varieties. Rpt. Long Ashton Res. Sta. 1965:136-138.

Williams, R.R. 1970. Factors affecting pollination in fruit trees. p. 193-207. In: L.C. Luckville and C.V. Cutting (eds.). Physiology of tree crops. Academic, London. 